\title{
Foetal Organ Implantation into Adult Animals: A Model for In Vivo Culture of stem cells?
}

\section{Coulic Véry ${ }^{1 *}$, Novikov VN ${ }^{1,3}$, Mboti $F^{1,4}$ and Delrée $P^{2}$}

${ }^{1}$ Translational Medicine Laboratory of the Brussels Free University, Brussels, Belgium

${ }^{2}$ Institute of Pathology and Genetics, Gosselies, Belgium

${ }^{3} \mathrm{NV}$ Sklifosovski Research Institute of Emergency Medicine, Moscow, Russia

${ }^{4}$ CHU Brugmann, Department of Thoracic, Endoscopic and Abdominal Surgery, Brussels, Belgium

*Corresponding Author: Coulic Véry, Translational Medicine Laboratory of the Brussels Free University, Brussels, Belgium.
Received: May 29, 2021

Published: June 29, 2021

(C) All rights are reserved by Coulic Véry., et al.

\section{Abstract}

Background: Presently stem cell implantations are more and more developed and applied in clinics as alternative and complementary solutions to adult organ transplantation because of the growing demand and capacities to provide these interventions, while lack of donors is patent. But some limitations of stem cell use remain (for instance integration within the recipient organism of engineered tissues and organoids obtained in vitro from stem cells). The use of foetal organ implantation into adult animals may be an alternative for in vivo study of stem cell development and evaluation of the host participation to this process. The objectives of this work were o try different foetal organ implantations into adult animals (part I) and to evaluate their use for repairing experimental lesions of some adult organs (part II).

Material and Methods:

- Part I: In > 650 experiments on rats and mice, different sites of foetal organ syngeneic implantation were proposed. Physiological (electric activity, motor and secretion activity) and morphological (per illumination, ultrasound and magnetic imaging, optic and electron microscopy) methods were used for implant development evaluation during up to 12 months.

- $\quad$ Part II: Foetal heart and foetal digestive organs were tested for both oesophagus circular defect and heart thermic lesion repair (38 and 29 rats). Trials with foetal pancreas implantation were provided in rats with diabetes induced by Streptozotocin and/ or protein deficit and in a small pilot group of diabetic patients.

Result:

- Part I: After a "dedifferentiation" phase, foetal organ implants could grow following ontogenetic pattern but - at least in our experimental conditions - some of them were not able to re-organize as a whole functional adult organ. The factors enhancing or limiting the organoid formation are considered.

- Part II: Foetal heart implants were proved to enhance heart lesion morphological and functional repair. Foetal oesophagus, stomach or intestine fragments combined with chitosan flaps ensured a complete restoration of the oesophagus wall after oval or segmental resection. Implantation of foetal pancreas was able to reverse Streptozotocin induced diabetes and to prevent chronic glucose disorders following protein deprivation in rats. In patients temporary positive influence was noted.

Citation: Coulic Véry., et al. "Foetal Organ Implantation into Adult Animals: A Model for In Vivo Culture of stem cells?". Acta Scientific c Gastrointestinal Disorders 4.7 (2021): 80-93. 
Conclusion: Implantation of different foetal organs into syngeneic adults may constitute a valuable model for theoretical studies of in vivo stem cell differentiation and organoid growth. The ear implantation site deserves special attention. Some interesting applications are possible and worthwhile to be discussed and developed.

Keywords: Foetal Organ Development; Precursor Cells; Stem Cells; Regenerative Medicine; Reparative Surgery; Surgical Experimental Models; Heart Repair; Oesophagus Defect Reconstruction; Diabetes Treatment

\section{Abbreviations}

BW: Body Weight; DM: Diabetes Mellitus; ESC: Embryonic Stem Cell; FH: Foetal Heart; FI: Foetal Intestine; FL: Foetal Liver; FPa: Foetal Pancreas; FOE: Foetal Oesophagus: FOI: Foetal Organ Implantation; IGF-1: Insulin-Like Growth Factor; M: Mean Value; MRI: Magnetic Resonance Investigation; MSC: Mesenchymal Stem Cell; PDDM: Protein Deficit Diabetes Mellitus; PTH: Parathyroid Hormone; PTHrP: Parathyroid Hormone Receptor Protein; RNA: Ribonucleic Acid; SD: Standard Deviation; US: Ultra Sound

\section{Introduction}

Taking into account the problems of adult organ transplantation (graft procurement, life lasting post transplantation treatment and its complications [1-7]), other solutions are presently envisaged in reparative/regeneration medicine and surgery: use of stem cell obtained from embryonic origin (ESC) or derived from different adult tissues by dedifferentiation in vitro (MSC) [8-10]. Studies about stem cell observation and use are developing in three directions: 1) comprehension of embryogenetic growth pattern [11-15], 2 ) investigation of the pathogenesis of some diseases and hence of possibility of influencing their course [16-18] and 3) practical use for tissue and organ repair [8,10,19]. Human organoids produced in vitro are more and more used for developmental, physiology and pathology investigations, for therapeutics trials, but not really in reconstructive surgery yet [20-26]. Presently, stem cell creation has now extended to industrial production for clinical applications [8,9,27-29]. But some questions remained open such as the degree of integration of implanted stem cells, their real role in restoration of leased organ function (replacement or boosting the own organ resources). In fact, stem cell use has fair results in tissue repair such as bone, cartilage and tooth structures, and haematopoietic and liver tissues. Biology of the ectopic development of the grafted tissues and growing organoids still remains weakly investigated, especially the possibilities of innervation by the host or inclusion into the neuro-humoral system of the organism regulation [30]. And in any way, stem cell and organoid are the result of an artificial production in vitro that may explain their difficulties really to become integrated into the organism where they are implanted even when this implantation is autologous.

The question is a little different, when we consider foetal tissue and organ transplantation.

Foetal organ transplantation into adult organisms is an old problem which study began in the 50 -ies of the XX century with foetal heart grafting [31,32] and extended later to foetal digestive organs $[33,34]$.

Foetal organ transplantation has two faces: theoretical one how perfect is the ectopic foetal organ growth, and practical one - how suitable the foetal organ graft is for reparative surgery. The main foetus organs were investigated: heart [35-46], digestive tract (intestine [47-51] oesophagus and stomach [52-57])], pancreas [58-65]; different digestive organs together [66-71], liver [72-78], lung [79], kidney [80], some of them more than others. The first studies on the foetal heart and intestine implantation into different sites (subcutaneous, in occulo, under spleen capsule and others) have already shown that the foetal implants could give growth to "adult-like" formations able, in certain conditions, to manifest functional activity. For instance, the foetal intestine, after sub cutaneous implantation on a rat spine was able to secrete if a stoma was managed [51], a foetal heart implanted into the anterior chamber of the eye was able to beat and react to adrenalin and acetylcholine injected to the host [35].

Implants of foetal pancreas were shown to be able to influence the manifestations of diabetes mellitus $[60,61,66]$.

But the moratorium imposed from 1970 up to 2009 to the studies involving embryos and foetuses has prevented the development 
of all side investigations [79]. And the possibilities of the "natural" in vivo growth process of ectopic cell, tissues and organ were poorly explored.

\section{Aim of the Study}

The aims of the present work was to try organ in vivo cultures by means of foetal organ implantations into adult animals (part I) and to evaluate their possibilities of use for repairing experimental lesions of adult organs (part II).

\section{Materials and Methods}

Experiments were carried on more than 650 adult Wistar and Fischer rats, and $\mathrm{C} 57 \mathrm{Bl}$ and BALBc mice both sexes, aged 2 - 6 months, according to Bioethics rules, and allowed by local Ethics Committee protocols $\mathrm{NN}^{\circ} 50,508$ and 690. All the surgical interventions and/or manipulations were performed under anaesthesia or sedation of the animals. The study was provided during a period beginning in 1978 [36] and extending up to 2020. The complete enumeration of the experimental series is presented in table 1.

\begin{tabular}{|c|c|c|c|}
\hline $\begin{array}{c}\text { Series } \\
\text { (implants) }\end{array}$ & $\begin{array}{c}\text { Implantation } \\
\text { site }\end{array}$ & $\begin{array}{c}\text { Animal nb } \\
\text { (recipients) }\end{array}$ & $\begin{array}{c}\text { Observation } \\
\text { delay }\end{array}$ \\
\hline \multirow[t]{2}{*}{ Fetal esophagus } & Ear, & 10 & 6 months \\
\hline & Neck & 30 & 9 months \\
\hline \multirow{2}{*}{$\begin{array}{l}\text { Fetal stomach, } \\
\text { intestine }\end{array}$} & Ear & $>100$ & 12 months \\
\hline & Neck & 23 & 6 months \\
\hline $\begin{array}{l}\text { Foetal umbilical } \\
\text { cord }\end{array}$ & Ear & 20 & 4 months \\
\hline \multirow{2}{*}{$\begin{array}{c}\text { Foetal heart } \\
\text { (FHI) }\end{array}$} & Ear & 30 & 14 months \\
\hline & Thorax & 40 & 12 months \\
\hline \multirow{2}{*}{$\begin{array}{c}\text { Foetal liver } \\
\text { (FLI) }\end{array}$} & Ear & 29 & 12 months \\
\hline & Spleen hile & 21 & \\
\hline \multirow{2}{*}{$\begin{array}{c}\text { Foetal pancreas } \\
\text { (FPI) }\end{array}$} & Ear & 104 & 9 months \\
\hline & Spleen hile & 14 & \\
\hline $\begin{array}{c}\text { Oesophagus } \\
\text { lesion + (GFOI) }\end{array}$ & Neck & $20+5$ & 13 months \\
\hline \multirow{2}{*}{$\begin{array}{c}\text { Heart lesion } \\
\text { Heart lesion + } \\
\text { FHI }\end{array}$} & Thorax & 20 & 6 months \\
\hline & & 40 & \\
\hline \multirow{2}{*}{$\begin{array}{c}\text { DM (SD or PDD) } \\
\text { DM + FPI }\end{array}$} & Ear, abdomen & $20+37$ & 6 months \\
\hline & & $34+38$ & \\
\hline
\end{tabular}

Table 1. Number of animals and experimental series. GFOI: Grown Foetal Oesophagus Implant; SD: Diabetes Induced by Streptozotocin; PDD: Protein Deprivation Induced Diabetes.
These experiments were performed in syngeneic system of transplantation to avoid bias from immunologic rejection reaction.

The schema of different operations is presented on figure 1.

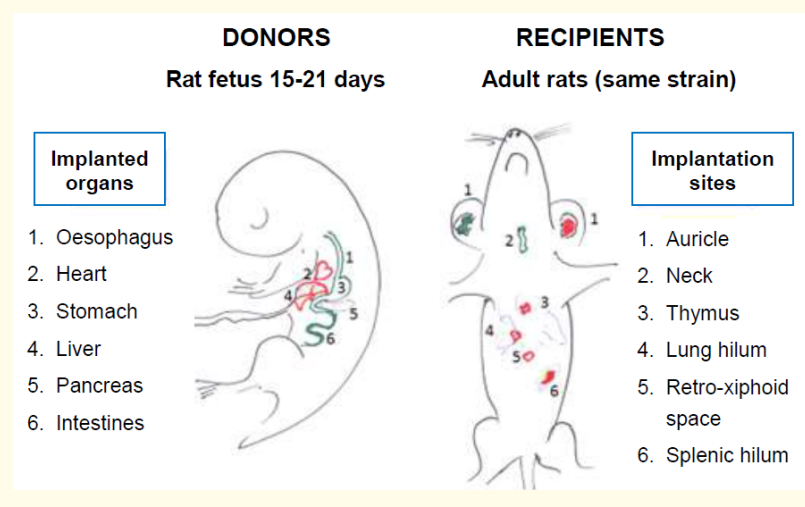

Figure 1

Donors were foetuses aged 14 - 20 days in utero. Under Fluorotane/Isofurane $4 \%$ pre-anaesthesia, and after intra peritoneal injection of Nembutal@ $0.75 \mathrm{mg} / \mathrm{kg}$ and of Temgesic(C) $0.5 \% 0.2 \mathrm{ml}$ as main anaesthesia, laparotomy of the gravid female was provided and the foetuses were extracted, the target organ was isolated and placed in a cup with saline at ambient temperature. In 10 cases donors were animals having received a foetal intestine segment which have begun to develop. A part of this growing implant was used as new graft (pricking or subculture).

Recipients were anaesthetized in the same way (except that last years, Nembutal was no more used and replaced by a mixture of Ketalar $^{\circledR}$, Diazepam $1 \%$ and Temgesic ${ }^{\circledR} 1 \%$ in equal quantities of $0.1 \mathrm{ml} / 100 \mathrm{~g}$ BW), after what a subcutaneous pouch was created within 2 - $3 \mathrm{~mm}$ after skin cut and blunt separation from the subcutaneous layer of the ear pavilion. A piece of oesophagus, stomach, intestine, liver, pancreas (volume $2-4 \mathrm{~mm}^{3}$ ) or the whole heart was introduced into the subcutaneous pouch. The skin wound was closed either by $8^{\circ \circ}$ Ethilon $^{\circledR}$ stich or by clay (Nobecutane $($ )). The same principle was used for implantation at the anterior neck region; the piece of foetal organ being placed at the caudal top of the salivary gland.

When thorax site was used, after complementary subcutaneous injection of Atropine 1\% $0.2 \mathrm{ml}$, intubation and start of artificial ventilation (UNO - Intermed - Penton, Sigma Delta, Netherland), a classical sternotomy was performed. The implant was either 
dropped into the cavity, or introduced under the pleura of the lung hilum, or under the thymus capsule, or fixed on the heart apex. After what the thorax was sutured by stiches layer after layer: sternum (Vicryl $2^{\circ \circ}$ ), muscles and skin (Vicryl $4^{\circ \circ}$ ).

In the case of abdominal implantation, laparotomy was performed and the implant was either dropped into the cavity or placed under the visceral peritoneum in the region of caecum or spleen hilum. The abdominal wall was sutured in 2 layers: peritoneum and muscles by a continuous catgut or Vicryl $4^{\circ \circ}$, the skin - by Vicryl $4^{\circ \circ}$ stiches.

Some experimental models of organ lesions were also used to test the foetal organ implantation as a way to correct them. They included diabetes mellitus induced by Streptozotocin ${ }^{\circledR}$ intra peritoneal injection $(75 \mathrm{mg} / \mathrm{kg}$ ) or by protein deprivation, and also oval or circular resection of the cervical oesophagus and thermic lesion of the heart apex, which are described other where [46,57].

After surgery the animals were placed into individual cages during the whole observation period in order to avoid competitive situations able to influence the survival and general condition of the animals.

Pilot study of human foetal pancreas implantation was also provided in 60 diabetic patients (1980 - 1992, Moscow, Academy of Medicine Scientific Research Institute of Artificial organs and Transplantation and District University Clinic ${ }^{\circ} 64$; authorization by the USSR Ministry of Health). After enlightened consent of the patient and the responsible gynaecologist, still born foetuses BW < $500 \mathrm{~g}$ were used as donors. Pancreas was procured and immediately transplanted into a subcutaneous pouch of the para umbilical region of the recipient under local (Xylocain 0.5\%) anaesthesia [60].

The investigation methods included:

- Clinical observation, BW evaluation (once/week during the $1^{\text {st }}$ month, further once/month),

- Physiological methods: Depending on concerned organ ECG (Mouse Monitor, UNO USA-NDL), radiography (standard clinics apparatus, General Electrics Digitalized, USA), ultrasound (Siemens MSH, with a 14, L5 SP probe), MRI (Philips, 1.5 Tesla), pH-measure.

- Biochemical methods: Analysis of blood and urines by strips for glucose and protein determination, determina- tion of IGF1 in recipient serum by Elisa method. Some foetal intestine implants were accurately separated from surrounding tissues, frozen in liquid nitrogen and kept at $-80^{\circ} \mathrm{C}$ till analysis. PTHrP mRNA and its receptor mRNA were quantified by RT- PCR in real time. Control investigations were provided on foetal intestines before grafting and intestines of rats at the same delays after birth as after implantation. Intact animals and animals after sham operations were also used for control.

- Morphological methods: Per illumination and graft dimension measures, optic (including immuno-histo-chemistry for glucagon, somatostatin and insulin determination in pancreas implants) and electronic microscopy of biopsy material, respectively fixed in Formaldehyde $12 \%$ or glutaraldehyde, embedded into paraffin or araldite. Slices of $4 \mu$ thickness were stained mainly by haematoxylin saffron eosin.

- $\quad$ Statistics: The number of observations was no less than 4 6 in each investigation, $\mathrm{M} \pm \mathrm{SD}$ were calculated, results were compared to control - intact animals or sham operation, using Student criterion (Td versus Tst). The measured difference was considered as valuable when $\mathrm{p}<0.01$.

The observation delays ran from day 0 to day 600 . Euthanasia was provided by intra peritoneal injection of pentobarbital $2^{*}, 1$ $\mathrm{ml} / 100 \mathrm{~g} \mathrm{BW}$.

The follow up of human recipients was usual for diabetic patients after any surgery including frequent blood glucose determination and assessment of the implant condition by regular US exploration of the anterior abdominal wall.

\section{Results}

Part I

Experiments have shown that some conditions are required to ensure the success of the implantation:

1. Short delay between isolation and implantation of the foetal organ, no more than $50 \mathrm{~min}$ (the shortest being the best) (Table 2).

2. A well vascularized bed/site for implantation.

3. Absence of immunological conflict, i.e. syngeneic grafting (allogeneic foetal grafts were rejected in the same classic way as adult one (Figure 2). 
4. Implantation of foetal organs by dropping them into the thorax or the abdominal cavity was a failure.

\begin{tabular}{|c|c|c|}
\hline Ischaemia (min) & 2 weeks & 4 weeks \\
\hline$<20 \mathrm{~min}$ & $31 / 31=100 \%$ & $29 / 29=100 \%$ \\
$30-50 \mathrm{~min}$ & $53 / 53=100 \%$ & $44 / 47=91 \%$ \\
$50-60 \mathrm{~min}$ & $15 / 16=94 \%$ & $8 / 12=66 \%$ \\
$=$ or $>60 \mathrm{~min}$ & $3 / 5=60 \%$ & $2 / 4=50 \%$ \\
\hline Total implants & $102 / 108$ & $83 / 92$ \\
\hline
\end{tabular}

Table 2: Survival of the syngeneic foetal heart implant (survival number/total implants) depending on "ischemia" delay.

NB: In all the animals both ears were used.

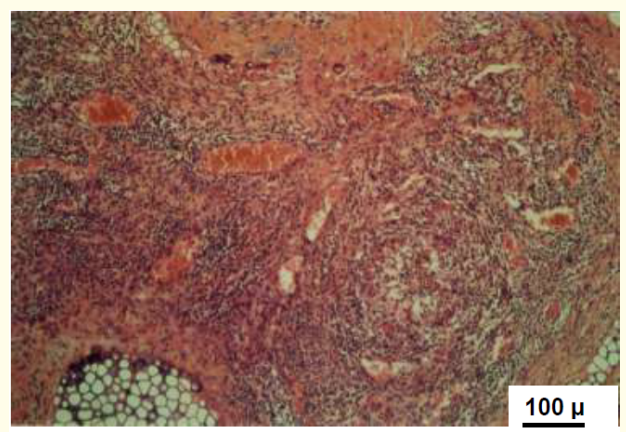

Figure 2

Implantation under thymus, salivary gland capsule as well as under the spleen hilum or the ileocecal angle visceral peritoneum, was successful in $50-75 \%$ of the cases.

Implantation into an ear pavilion subcutaneous pouch presented the possibilities of visualization of the implant evolution, of the measure of the graft dimensions and vascularization features (Figure 3), as well as biopsies procurement.

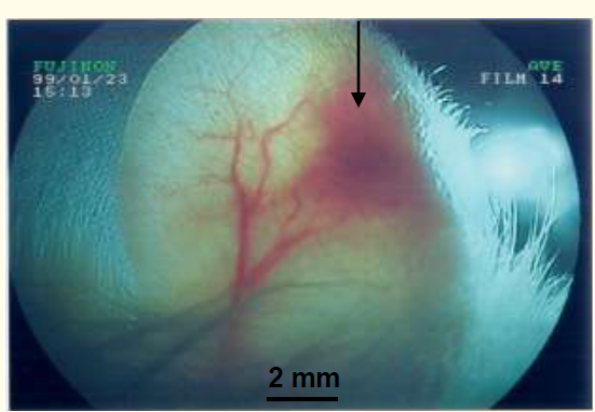

Figure 3
During the first days, independently on the implanted foetal organ concerned, the evolution of the implant was the same - the specific organ structure was replaced by a kind of infarcts with cell apoptosis and necrosis and the predominance of undifferentiated cells (Figure 4).
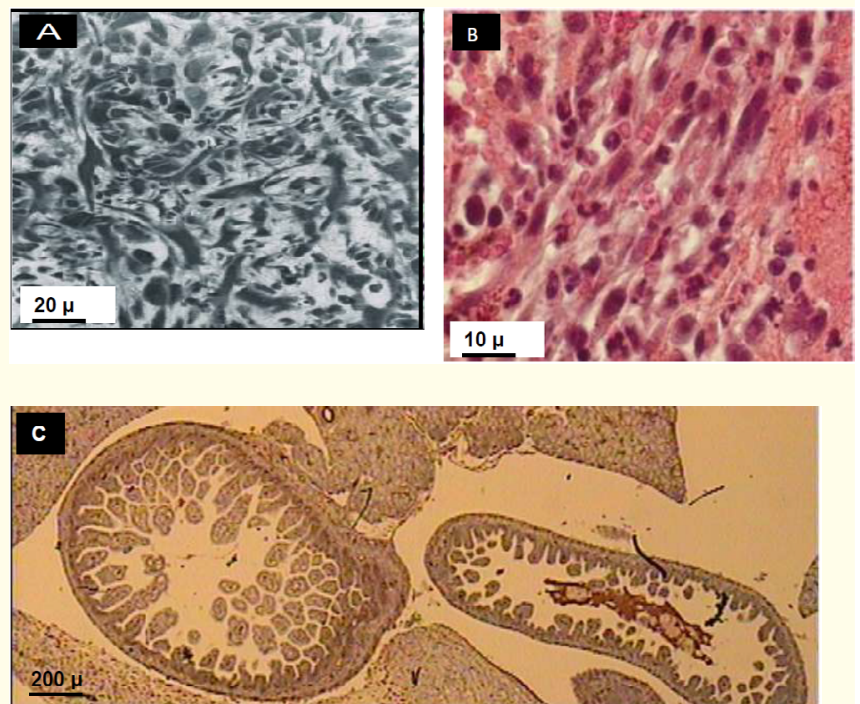

Figure 4

At these observation delays it was even difficult to identify the nature of the implant.

Penetration of recipient capillaries into the graft and their connection with the graft lacunas were observed about 5 - 7 days after operation.

During the next weeks, differentiation of tissues was realized according to ontogenetic pattern specific to the implanted organ (Figure 5).

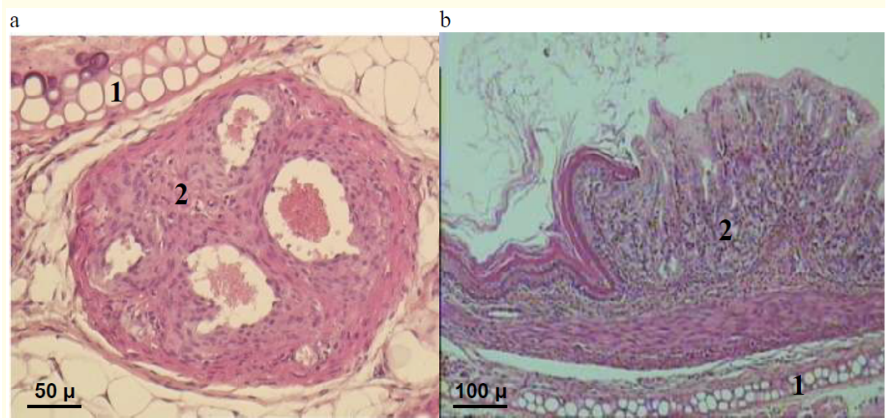




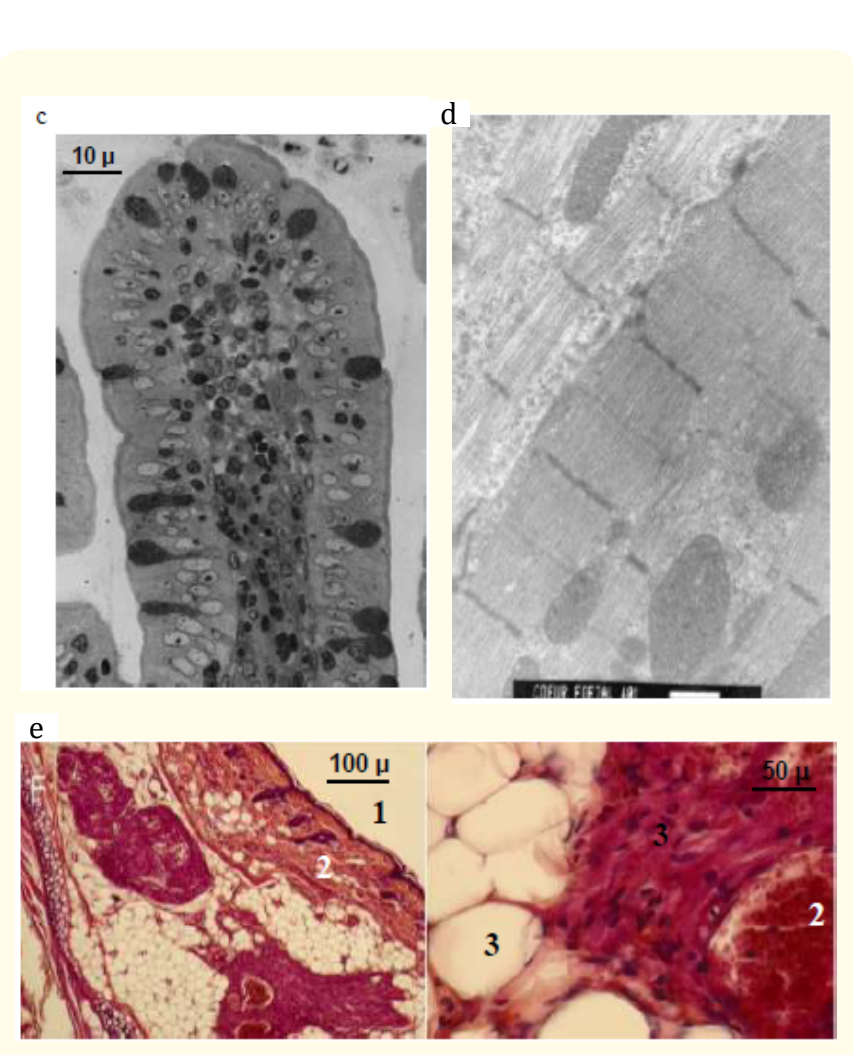

Figure 5

An exception was noted when umbilical cord was implanted: the placental end did not develop as an organ, and the foetal third containing allantois, developed as a small intestine.

As an exception, teratomas were observed in 3 cases, when very young donors (BW < 1g) were used [See also 90, 91]. If the whole material (parts 1 and 2) is considered, that is more than 650 operations. 6 cases were detected, i.e. $0.36 \%$.

According to first investigations IGF-1, PTH and PTHrP levels were slightly elevated at day 7 - 14 post operation. PTH was high in normal foetal intestines and slowly decreased after birth. In the case of ectopic development a slight decrease was noted during the first days, that corresponded to the necrosis and apoptosis noted in the graft. At days 7 - 9 a pike of activity was expressed, corresponding to the beginning of the re-formation of the grafted intestine. On the contrary, PTHrP expression has shown a trend to decrease. As to IGF-1, the elevation of its blood level was maximal reaching 150 - $200 \%$ of its initial and control levels at the end of the second post operation week and remained significantly higher than control during the further 4 - 6 months (Table 3).

\begin{tabular}{|c|c|c|c|c|}
\hline $\begin{array}{c}\text { Observation } \\
\text { delay }\end{array}$ & $\begin{array}{c}\text { Foetal } \\
\text { intestine } \\
\text { and } \\
\text { stomach }\end{array}$ & $\begin{array}{c}\text { Foetal } \\
\text { heart }\end{array}$ & $\begin{array}{c}\text { Foetal } \\
\text { pancreas }\end{array}$ & $\begin{array}{c}\text { Signifi- } \\
\text { cance (vs } \\
\text { control) }\end{array}$ \\
\hline $\begin{array}{c}\text { Control } \\
\text { intact) }\end{array}$ & $460 \pm 31$ & $460 \pm 31$ & $460 \pm 31$ & \\
\hline Day 4 & $599 \pm 130$ & $589 \pm 37^{*}$ & $689 \pm 200$ & ${ }^{*} \mathrm{p}<0.01$ \\
\hline Day 9 - 14 & $\begin{array}{c}1120 \pm \\
200^{*}\end{array}$ & $\mathrm{~nm}$ & $713 \pm 58^{*}$ & ${ }^{*} \mathrm{p}<0.01$ \\
\hline Month 2 - 3 & $922 \pm 85^{*}$ & $\mathrm{~nm}$ & $672 \pm 25^{*}$ & ${ }^{*} \mathrm{p}<0.01$ \\
\hline Month 6 & $624 \pm 56^{*}$ & $608 \pm 80^{*}$ & $498 \pm 11$ & ${ }^{*} \mathrm{p}<0.01$ \\
\hline
\end{tabular}

Table 3: First results of IGF-1 determination in recipient sera (ng/ml).

The grown implants of foetal heart, intestine, stomach, and oesophagus have proved to be functional: motility, secretion for intestine and stomach, presence of a cardiac rhythm and blood flow for the heart were detected (Figure 5 and 6). As to liver and pancreas, adult structures were obtained but not an organ functioning as a whole. So liver has shown bile system and hepatocyte columns with sinusoids, but no sign of bile elaboration. The grown foetal pancreas developed pancreatic tubes, sometimes acinar formations and endocrine cells immune-positive for insulin, glucagon and somatostatin. But no pancreatic organization was observed. Nevertheless foetal pancreatic implants have shown functional activity (See also [49,51,57]).

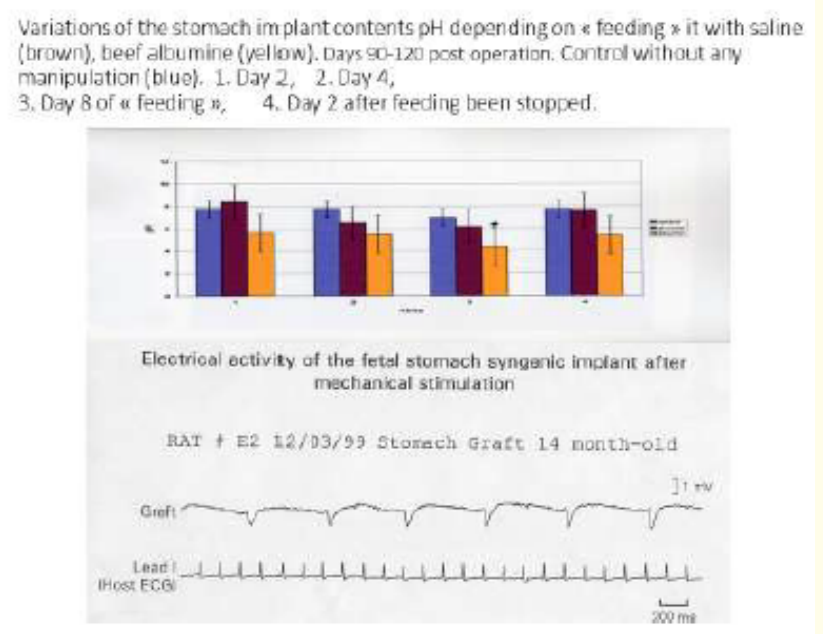



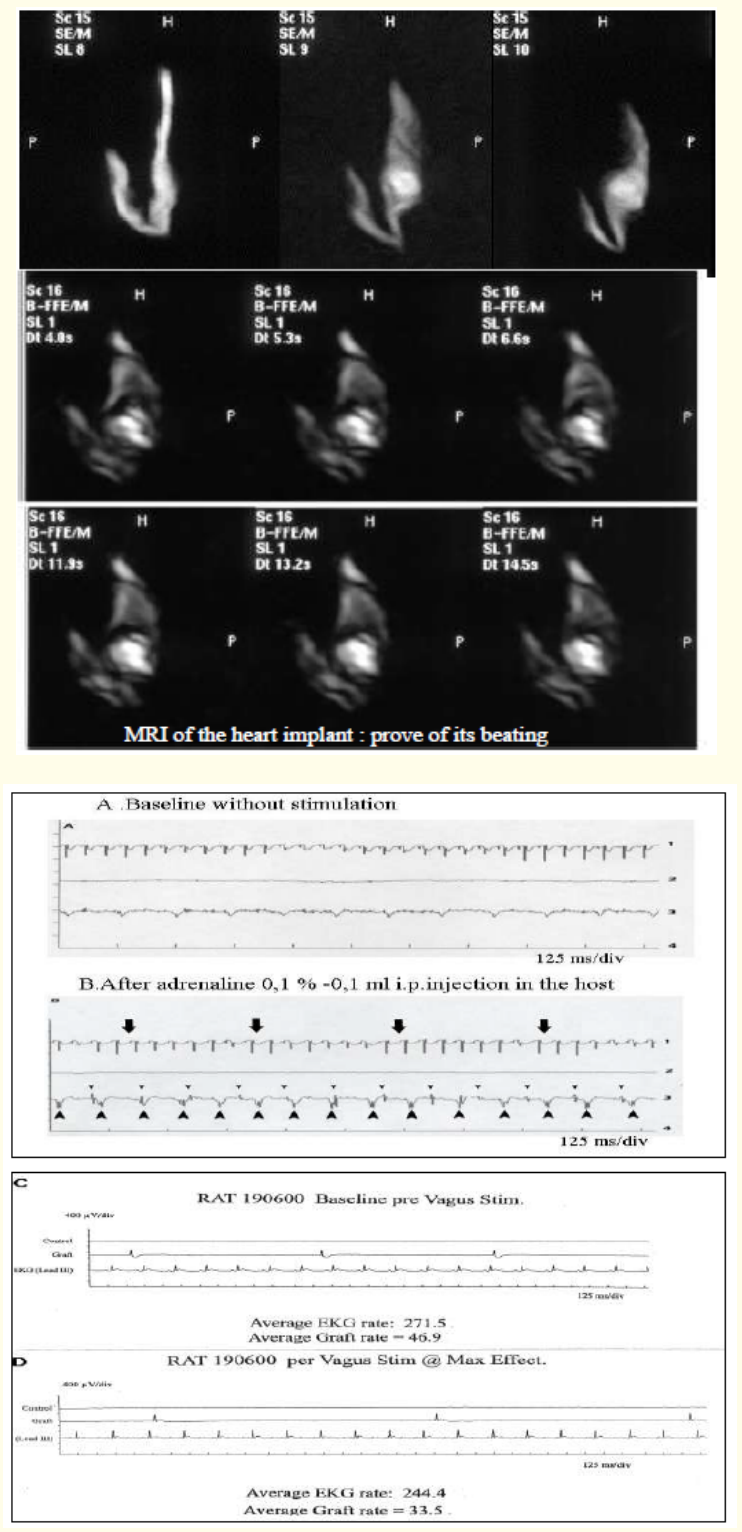

Figure 6

In late delays (8 - 11 months) the implants have shown signs of aging: fibrosis or adipose degeneration (See figure $5 \mathrm{e}$ ).

In the short series with "pricked" or sub cultured growing foetal intestine implant into another adult rat at the ear site, at days 14 intestinal mucosa with villi formation was observed in the secondary developing implant (Figure 7).
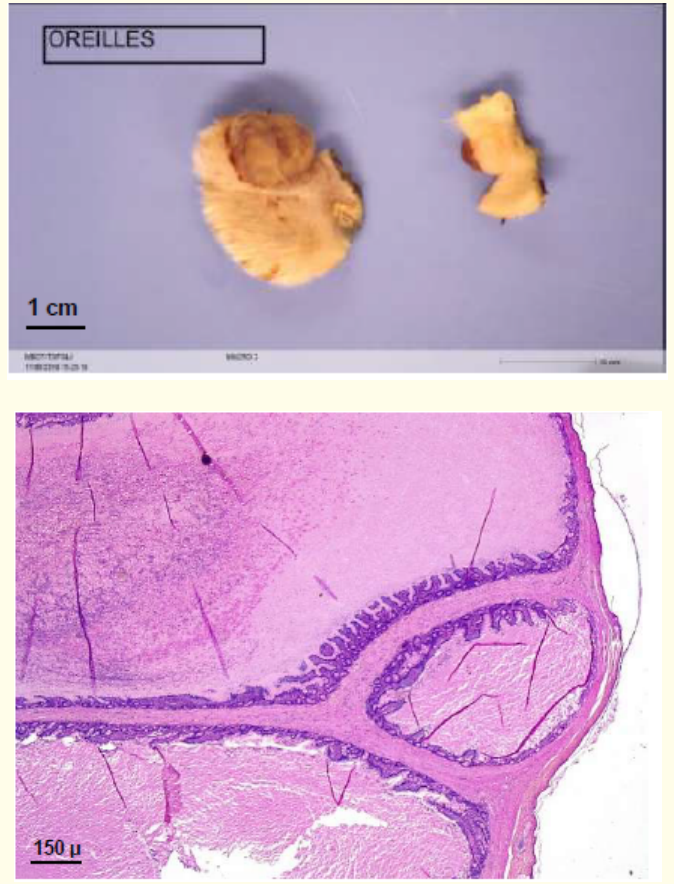

Figure 7

\section{Part II}

Experiment results have been presented in several publications [60-64].

They can be summarized as following:

- In animals with DM induced by Streptozotocin, it was possible to stop glycosuria and to reach complete normalization of glycaemia within 2 - 4 months under certain conditions including a sufficient quantity of implants, 4 as a minimum and the more possible being the best.

- In rats with PDDM a significant effect was observed for prevention of DM development. When foetal pancreas implantation was provided at the same time as the normal feeding restoration, rehabilitation of BW and morphologic differentiation between males and females was accelerated in comparison with not grafted controls and no diabetes was observed later in grown animals.

- Human foetal pancreas grafting, also provided in 60 patients with DM 1 and DM2 in years 1980 - 1990, has induced, in $70 \%$ of the cases, a significant but temporary 
amelioration of their condition. This manifested by an important fall of needed insulin injection doses (up to 80\%) a regression of the disease complications such as neuropathy and impotency, and a stabilization of nephropathy and retinopathy. The effect duration varied between 3 and 24 months, in 1 case it prolonged several years. In spite of the absence of immunosuppressive treatment, no acute rejection was observed, but development of the implant fibrosis detected at US investigations testimonies in favour of a chronic rejection process. No other complication was detected during the several yearlong observation of the patients.

- $\quad$ Foetal oesophagus or stomach segment combined with chitosan tubular compact prosthesis has allowed a complete healing of circular defects of the cervical oesophagus without complication in $72.4 \%$ of the cases (versus $43 \%$ in control series with chitosan tube alone. (for details, see [56,57]).

- $\quad$ Foetal heart implantation under chitosan cover immediately after thermic injury of the ventricle apex (diameter $0.8 \mathrm{~cm}$ ) on the site injury, has accelerated functional and morphological repair of the organ: the injured heart functional and morphologic restoration was complete within 4-6 months after operation, whereas the recovering in control series remained partial even within 12 months (for details -see [46]).

\section{Discussion}

As shown in our and different authors experience, analysis of foetal organ implantation results are conditioned by different external and internal factors influencing the graft development. Among them "ischaemia" duration, implantation site peculiarities, especially vascularization, general condition of the recipient, but also the foetal organ peculiarities are to be considered.

The comparison of the different surgical models of foetal organ implantation used in our study has shown that the best results (up to $95-100 \%$ success) were obtained in the case when the warm ischemia duration did not excess $50 \mathrm{~min}$, and the shortest was the best. We did not use cooling of the procured organs, as far as preliminary tests were negative: cold altered foetal cell condition.

Important too that the implantation site was well vascularized: under the skin, gland capsules or visceral peritoneum, or within a subcutaneous pouch of the ear pavilion. Spleen or liver or kidney superficial parenchyma are well known implantation sites; which also satisfy to the same criteria of rich vascularization, as well as anterior eye chamber $[35,36]$ and probably the vestibule cochlear nerve [80].

The subcutaneous pouch of ear pavilion, first proposed by Fulmer., et al. in 1963 [32], seems to be an original implantation site and has shown different advantages: simple, easy to perform and not very traumatic operation, well tolerated by animals, allowing visual observation, measures, biochemical and physiological investigations of the implant, procurement of biopsy material. Last preliminary experiments suggest that it might be used for precursor cells culture and selective development. The only inconvenient seems to be the limited extension volume for the implant growth.

The neck implantation site ensured place enough from even enormous growth of intestine or stomach adult-like cysts. In our experiments we did not ensure the exit of secreted mass, though it is possible and has spontaneously occurred in some cases. This model might present interesting perspectives for physiological studies of the grown implant (For instance pH determination, motility detection and so on).

The evolution of the implanted foetal organ has shown different phases. First, a "destructuration-dedifferentiation" phase during the first week after operation. From day 2 to day 5 - 7 the observed picture may be interpreted either as regression, dedifferentiation of the organ structures, or as the result of mature cells necrosis whereas weakly differentiated ones survived and gave a new development after a while. Unfortunately, up to now we have not had the possibility to perform the necessary tests with stem cell marking or determination of host/graft cells into the mixture of lymphocytes, fibroblasts and other not identified cells. Interesting that at this moment it was difficult to identify the very origin of the graft (See figure $4 \mathrm{~A}$ and $4 \mathrm{~B}$ ). Phase 2 is characterized by vascularization of the graft and differentiation of the "magma" cells which formed an adult like organ at the end of the first post implantation month. During phase 3 the structure stabilized and function developed, maintaining during several months. Phase 4 was characterized by aging phenomena, morphological and functional degradation.

Nevertheless, during the second phase of re-differentiation, the reconstitution and development of the implanted organ was specific and never deviated from the ontogenetic pattern. Even when we tried umbilical cord implantation and obtained the growth of an intestine, that may be explained by the presence of the allantois, 
coming from endoderm and primary intestinal tube. These observations mean that re-differentiation probably occurs from precursor cells already organ determined. This also signifies that the first phase is worthwhile further investigations not only for cell identification, but also in order to influence both their differentiation and development, and possibly to modulate their antigenicity.

It is necessary to note that we observed the growth of teratoma in 6 cases (out of more than 650 operations), including 2 cases of malignancy. This was previously discussed $[81,82]$, but it is important to underline that it always occurred: $1 /$ when the donor was very young ( $<1 \mathrm{~g} \mathrm{BW},<12$ day in utero age) and so could contain embryonic multipotent stem cells, and 2 / when the foetal organ was implanted into a zone of the adult organism, where stem cells could be easily mobilized (posterior mediastinum, cervical oesophagus zone). The absence or the small quantity of pluripotent stem cells in the implant procured from donors in the last third of gravidity, might be a warrant of its correct development, without tumour deviance.

We have also observed that only hollow organs containing an intramural nervous system or a conduction system and expressing motility capacity as oesophagus, stomach, intestines and heart, were reconstituted as whole organs with organized and long lasting effective physiological activity. As to liver and pancreas, their constitutive elements were present, but coordinated activity of the organ as a whole was absent (for instance, no sign of exocrine secretion both in pancreas and liver was detected). Nevertheless, functional activity was patent: in pancreas - ability to influence diabetes evolution in rats after Streptozotocin injection [60,62,63], in liver - capacity to correct specific pathology $[73,76]$. These organs are innervated differently, without a "peripheral brain" within them. Is this the cause of the different evolution of the implant? Besides, studies about re innervation of stem cell or islet cell implants were started but without strong conclusions].

Interesting also to observe that some growth factors values have been elevated in the graft tissue homogenate and in the recipient blood after operation. Both PTH/PTHrP expression and significant growth of IGF1 in the recipient serum were registered beginning from the second week after operation (beginning of the $2 \mathrm{~d}$ phase of the graft evolution) when the first connexions between the host vascular web and the graft are realized and the graft began to differentiate again. Later the PTH and PTHrP level evolution did not significantly differ from control. On the contrary the IGF1 increase reached up to $150 \%$ and more than its initial value. This elevation lasted all through the second and third phases, during which the implant morphologically and functionally looked like an adult organ. Interesting that boosting IGF-1 delivery by the liver has also enhanced the success rate of foetal pancreas implantation $[62,65,71]$.

Following the previous observations and reflexions, the question of the respective role and mutual interactions of donor and recipient in the implant development must arise. For instance, why did the host IGF1 levels remain significantly high during months that corresponds to the $2 \mathrm{~d}$ and $3 \mathrm{~d}$ phases of the foetal intestine and heart implant growth? They normalized later at the $4^{\text {th }}$ phase when aging and fibrous or adipose degeneration of the graft developed. What is the origin of this phenomenon and its mechanisms? Where the IGF1 comes from: from the graft, from the host liver, from both? Is the IGF-1 increase a promoting factor of the implant development or a consequence of the implantation and development of the graft, or both? What are the adult organism limits of stem cell mobilization for tissue and organ repair? and interaction with the graft? How to influence these phenomena and avoid deviances like tumour formation? Nervous plexus and neurons were described in the digestive tract foetal implants: what is their origin - the graft stem cells or a penetration into the graft of host nervous system?

Presently this work cannot give any answer neither to the above mentioned questions nor to the question of the origin of the grown implant cells (only implant or with host participation). Deeper analysis and complementary investigations are needed. The possibility of the developed implant integration to the host organism needs convincing proofs (that is especially important for heart repair). Implants of digestive organs were morphologically distinct from recipient tissues except when implantation was performed into a lesion site like oesophagus defect. Foetal heart implants behaved in the same manner: when performed in the site of heart apex injury, in last delays close contact with recipient tissues was often observed. But we have no liable proofs of any degree of the implant integration. For that, a liable marking of either donor cells or recipient ones is necessary. It ought to be the aim of further studies. Nevertheless, the results observed in our trials with foetal oesophagus-stomach-intestine use for oesophagus defect repair or with implantation of foetal heart on the site of a thermic injury of the heart apex, were positive. Even foetal pancreas implantation, 
ensuring endocrine development and function, has given positive results in experiment as in cautious clinical trial. Besides the delay of the graft function was long enough to suppose that islet cells could be renewed, thanks to the presence in the implant of pancreatic tubules, source of endocrine cells of the organ all its life long.

Indeed, the described operations may be proposals of surgical models, simple for execution, relatively cheap and easy in management. They are not exclusive: a lot of foetal organs was not tested here, such as brain, kidney, lung, and other implantation sites are also possible, many of them having been mentioned in literature. Our studies have many common features with organoid creation studies, except that the last are started in vitro and their growth can be obtained from other organs of the same embryonic sheet (for instance intestine crypt cells can give growth to pancreas) by experimental monitoring means [14].

Foetal organ implantations seem to be valuable surgical models, allowing the study of different stem cell category involvement during foetal organ implant growth. They open wide possibilities to experiment in vivo new methods of influencing (boosting, slowing or modifying) the foetal organ graft development. They might be an intermediary step between in vitro studies and clinical applications (for instance, in the field of tolerance research, for instance by donor pre-treatment $[58,59]$. Are they concurrent with organoid investigations taking into account the tremendous development of research in this domain $[9,10,30]$ ? Probably not, they would be rather complementary, because foetal organ transplantation has the advantages to ensure a whole process in vivo with a good vascularization, and a natural humoral environment. So, we hope that this work will be useful for further researches and experimentations in the field of reparative surgery and regenerative medicine.

In summary: FOI presents significant positive sides, such as

- Accessibility: Of procurement in animals and even in humans (abortum, deep premature).

- Minor surgery for the recipient, and easy manipulations under analgesia or light anaesthesia.

- Large perspectives of theoretical studies including research on biological tolerance.

- Numerous possible applications in regenerative medicine and reconstructive surgery.
Nevertheless FOI significant negative sides are also o be considered, such as:

- Necessity of taking into account immunological incompatibility (at least presently) in case of possible clinical application.

- $\quad$ Ethical considerations, which arose a long time ago [83]. The concern both animal use (though surgical intervention is minimal and the foetal organ growth, as well as not invasive physiological and morphological investigations, seemed well tolerated by recipients); and involvement of human foetuses (though a foetus is a child and the parents are responsible of their child and must have the possibility to give their enlightened consent to foetal organ donation).

- Possibility of teratoma development, though it happens only under determined conditions.

\section{Conclusion}

1. Surgical implantation of foetal organs with its features of early regression followed by ontogenetic development seems to be an interesting model of in vivo investigations for descriptive and interventional developmental biology.

2. The ear site allows delicate dynamic observations with pointed biochemical, physiological, imaging and optic/electronic microscopy methods.

3. As preliminary investigations have suggested, foetal organ (for instance intestine) syngeneic implantation into an adult animal may be used as a method of in vivo precursor cells and tissue culture.

4. Implantation of different foetal organs might also be applied to clinical purposes in relatively short delays. The main problems to resolve (apart ethics) are: a) development of acquired immunological tolerance rather than recipient immunosuppression and b) constitution of foetal tissue/organ banks with in vitro as well as in vivo storage (See [15]).

5. Anyway the moratorium on FOI investigations has to be suppressed not only administratively and officially, but really, in order to make possible the serious studies that FOI is worthwhile. 


\section{Acknowledgements}

The authors express their deep and grateful thanks:

- For their contribution to functional and morphological evaluation of the foetal organ implants.

- $\quad$ To Dr J. Hustin (now retreated) from IPG, Dr C. De Prez and her technicians Mss G van der Gucht and N Lopez from the Pathology department of the Brugmann CHU, Prof. P. Deltenre from the laboratory od Evoked Potentials if the Brugmann CHU, Dr N. Hermanus (†), M. P. Reignaut, Dr ES Najar fom the Medical Imaging of the Brugmann CHU, Prof. J. Collette from the ULg Laboratory of immune-chemistry, Ms N. Neys from the ULB Laboratory of Experimental/Medicine.

- For insuring the surgical interventions when we were no more able to perform them, to Dr S Quéron and Dr F Mboti.

- $\quad$ For help and participation to Dr K Mbulava Mava and Dr P Furugyan during the Moscow PFU named by P Lumumba.

- $\quad$ For guidance and support to prof. P Bergmann and F Corazza, ex director and director of the ULB Laboratory of Experimental Medicine/further of Translational Research, Dr E De Koster from the Gastroenterology Department of CHU Brugmann.

- $\quad$ For logistic help to Ms M Leroy and M. J-L Kempeneers.

- And, at last but not least, to Ms Y Coulic Messe, for her everlasting support and participation.

\section{Disclosures or Conflict of Interests}

None.

\section{Bibliography}

1. Stites E., et al. "Current status of pancreas transplantation". Current Opinion in Nephrology and Hypertension 25.6 (2016): 569.

2. Lucan VC and Berardinelli L. "Gastrointestinal side effects of post-transplant therapy". The Journal of Gastrointestinal and Liver Diseases 25.3 (2016): 367-373.

3. Grochowiecki T., et al. "Surgical complications related to transplanted pancreas after simultaneous kidney and pancreas transplantation". Transplantation Proceedings 99.3 (2014): 2818-2821.
4. Young AL., et al. "The effect of liver transplantation on the quality of life of the recipient's main caregiver: a systematic review". Liver International 37.6 (2017): 794-801.

5. Shahrestani S., et al. "Outcomes from pancreatic transplantation in donation after cardiac death. A systematic review and meta-analysis". Transplantation 101.1 (2017): 122-130.

6. Cypel M., et al. "International Society for heart and lung transplantation after circulation death. Registry report". The Journal of Heart and Lung Transplantation 34.10 (2015): 1278-1282.

7. Minambre E., et al. "Improving the outcomes of organs obtained from controlled donation after circulatory donors using abdominal normothermic regional perfusion". American Journal of Transplantation (2017).

8. Ishii T and Eto K. "Foetal stem cell transplantation: past, present and future". World Journal of Stem Cells 6.4 (2014): 404420.

9. Liu G., et al. "Advances in pluripotent stem cells: history, mechanisms, technologies and applications". Stem Cells Review and Reports 16 (2020): 3-32.

10. Ntege EH., et al. "Advances in regenerative therapy: a review of the literature and future directions". Journal of Stem cells and Regenerative Medicine 14 (2020): 136-143.

11. Rolandson E., et al. "MSC from fetal and adult lungs possess lung-specific properties compared to bone marrow-derived MSC". Scientific Reports (2016): 6.

12. Van Vliet P., et al. "Fetal and adult cardiomyocyte progenitor cells have different development potential". Journal of Cellular and Molecular Medicine (2020).

13. Marcus AJ and Woodburry D. "Fetal stem cells from extra-embryonic tissues; do not discard". Journal of Cellular and Molecular Medicine 12.3 (2008): 730-742.

14. Chen YJ., et al. "De novo formation of insulin-producing "neo $\beta$ cell islets" from intestinal crypts". Cell Reports 6.6 (2014): 1046-1058.

15. Morizane R., et al. "Concise review: Kidney generation with human pluripotent stem cells". Stem Cells (2017).

16. De Filippis L., et al. "CNS Neural stem cells and human induced pluripotent cells to model rare CNS diseases". CNS and Neurological Disorders - Drug Targets 16.8 (2017): 915-926. 
17. Wu L-J., et al. "Organoids of liver diseases". World Journal of Gastroenterology 25.16 (2019): 1913-1927.

18. Little MH and Combes AN. "Kidney organoids: accurate models or fortunate accidents?" Genes and Development 33.19-20 (2019): 1319-1345.

19. Larijani B., et al. "Stem cell therapy in treatment of different diseases". Acta Medica 50.2 (2012): 79-96.

20. Wang W., et al. "Development of islet organoids from H9 human embryonic stem cells in biomimetic 30 scaffolds". Stem Cells and Development (2017): 11.

21. Velasco S., et al. "Individual brain organoids reproducibility from cell diversity of the human cerebral cortex". Nature 570.7762 (2019): 523-527.

22. Y Shi., et al. "Vascularized human cortical organoids (VOrganoids) model cortical development in vivo". PLOS Biology 18.5 (2020): e3000705.

23. Little MH and Combes AN. "Kidney organoids: accurate models or fortunate accidents?" Genes and Development 33.19-20 (2019): 1319-1345.

24. Wimmer RA., et al. "Human blood vessel organoids as a model of diabetic vasculopathy". Nature 565.7740 (2019): 505-510.

25. Almeodadi M., et al. "Gut organoids: mini-tissues in culture to study intestinal physiology and disease". The American Journal of Physiology: Cell Physiology 317.3 (2019): C405-C419.

26. Daoud A and Mulnera JO. "Insight into human development and disease from human pluripotent stem cell derived intestinal organoids". Frontiers in Medicine (2019).

27. Park D., et al. "Concise review: Stem cell microenvironment on a chip: current technologies for tissue engineering and stem cell biology". Stem Cells Translational Medicine 11 (2015): 1352-1358.

28. Natalwala A and Kunath T. "Preparation, characterization, and banking of clinical-grade cells for neural transplantation: scale up, fingerprinting and genomic stability of stem cell lines". Progress in Brain Research 230 (2017): 133-150.

29. Ruidant L. "La culture d'organoïdes humains est en plein essor; Le Journal du Médecin, 12 février 2482 (2017): 28.

30. Suradip Das., et al. "Innervation: the missing link foer biofabricated tisues and organs". NPJ Regen Medicine 5 (2020): 11.
31. Poor E. "Brephoplastic homotransplantation of hamster heart: a preliminary report". Transplantation Bulletin 4 (1957): 143144.

32. Fulmer RI., et al. "Transplantation of cardiac tissue into the mouse ear". The American Journal of Anatomy 118 (1963): 273-281.

33. Zinszar SN., et al. "Enormous organ)like growth of transplants of fetal digestive ract”. Transplantation 11.5 (1971): 499-501.

34. Tumyan BG., et al. "Suppress of tumors and transplants of fetal digestive tract growing in new born mice". Journal of the $\mathrm{Na}$ tional Cancer Institute 52.1 (1974): 63-69.

35. Tucker DC., et al. "Pacemaker development in embryonic rat heart cultured in oculo". Pediatric Research 23 (1988): 637648.

36. Bishop SP., et al. "Morphological development of the rat heart growing in oculo in the absence of hemodynamic work load". Circulation Research 66 (1990): 84-102.

37. Ménasché P. "Cell transplantation in myocardium". The Annals of Thoracic Surgery 75.6 (2003): 0-28.

38. Coulic V., et al. "Cardiomyoblast implantation (First results). Proceedings of the XIVth ISDQP International Congress "Diagnostic molecular pathology: from genomics to proteonics". Proceedings (2001): 66.

39. FH Etzion S., et al. "Influence of embryonic cardiomyocyte transplantation on the progression of heart failure in a rat model of extensive myocardial infarction". Journal of Molecular and Cellular Cardiology 33 (2001): 1321-1330.

40. Yao M., et al. "Long term outcome of foetal cell transplantation on postinfarction ventricular remodeling and function". Journal of Molecular and Cellular Cardiology 35 (2003): 661-670.

41. Lebon B., et al. "Myoblasts transplanted into rat infarcted myocardium are functionally isolated from their host". Proceedings of the National Academy of Sciences of the United States of America 100 (2003): 7808-7811.

42. Quéron V Coulic., et al. "Fetal heart transplantation: influence of some factors". European Society for Organ Transplantation ESOT (2015): P447.

43. Quéron S., et al. "About the use of fœtal heart implants for heart lesion repair in rats". ESOT 2017 abstract N 3734855. Session Basic Heart Surgical Technique, Brief Presentation BOS (2017): 196. 
44. Coulic V., et al. "Heteroppopic implantation of fetal heart in sungeneic adult rats (Comparative study of growth conditions, limits and perspectives)". American Journal of Biomedical Science and Research 7.1 (2020): 57-67.

45. Quéron S., et al. "Heart lesion repair by fetal heart implantation and chitosan flap in rats". Transplantation Research Journal 3.1 (2020): 1-13.

46. Leapman SB., et al. "Transplantation of fetal intestine. Survival and function in a subcutaneous location". Annals of Surgery 179.1 (1974): 109-114.

47. Krylova NV., et al. "Comparative evaluation of microcirculation vessels of the bed of tumoral and fœtal intestine implants » // 12th Congress of the ESSR (1978): 2119.

48. Ferguson A and Parrot DMV. "Growth and development of "antigen free" grafts of fetal mouse intestine". The Journal of Pathology 106.1 (1979): 95-101.

49. Jolma BVM., et al. "Differences in the development pf jejunum and ileum as observed in fetal rat intestinal grafts. Possible implications related to villus size gradient". The American Journal of Anatomy 158.2 (1980): 211-215.

50. Kulik (Coulic) VP., et al. "Transplantation of the fetus small intestine to adult animals". Sechenov Physiology Journal 80 (1994): 78-87.

51. Coulic V., et al. "Experimental comparative evaluation of the functional capacities of ectopically grown fetal organs". Russian Journal of Physiology 91.4 (2005): 408-430.

52. Yamataka A., et al. "Fetal esophageal transplantation in rats: a treatment option for long-gap esophageal atresia". Journal of Pediatric Surgery 34 (1999): 38-40.

53. Angioi K., et al. "Morphological and functional development of whole human fetal stomachs grafted nude mice". Development Growth and Differentiation 43 (2001): 425-435.

54. Coulic V., et al. "Transplantation of fotal oesophagus and stomach: perspectives for reparative gastroenterological surgery". Vestnik Khirurg Gastroenterology 1 (2006): 112-123.

55. Najar ES., et al. "Imaging oesophagus defect reconstruction". Journal of Clinic Cases Studies 3.2 (2018): 1-5.

56. Vandaele S., et al. "Combined bio-prosthesis for oesophagus defect repair(Experimental study)". EC Gastroenterology and Digestive System 5.11 (2018): 854-871.
57. Garvey JFW., et al. "Experimental transplantation of fetal pancreas and isolated islets in the rat: srudies of the donor pretreatment and recipient immune suppression". Transplantation Proceedings 12.4-2 (1980): 186-189.

58. Hardy MA., et al. "Foetal pancreatic islet transplantation: immune-alteration with ultraviolet irradiation". World Journal of Surgery 8.2 (1984): 207-213.

59. Kulik (Coulic) VP., et al. "Fetal pancreatic implantation without conservation in diabetic patients". Journal Sovietskaya Medicina (1987): 16-22.

60. Furugian P., et al. "[Experimental protein deficient diabetes and methods of correcting it]". Bulletin of Experimental Biology and Medicine 112.10 (1991): 350-352.

61. Coulic V., et al. "IGF-1 in fetal pancreas transplantation Chinese". Medical Sciences Journal 8.62 (1993): A004.

62. Coulic VP., et al. "Transplantation of the fœtus pancreas to adult animals". Sechenov Physiological Journal 80.10 (1994): 111-118.

63. Coulic V., et al. "Morpho functional peculiarities of ectopic fœtal pancreatic growth". Acta Gastro enterologica Belgica 59.1 (1996): 62.

64. Adams GA., et al. "Augmenter of liver regeneration enhances the success rate of fetal pancreas transplantation in rodents". Transplantation 65.1 (1998): 32-36.

65. Reinholt FP., et al. "Survival of fetal porcine pancreatic islet tissue transplanted to a diabetic patient: findings by ultrastructural immunocytochemistry". Xenotransplantation 5.3 (1998): 222-225.

66. Coulic V., et al. "Combined implantation of several organs into syngenic adult animals (first results)". Acta Gastro-enterologica Belgica 64.6 (2001): B01.

67. Coulic V., et al. "Factors influencing fetal digestive organs ectopic growth. In: Eurem, Dublin (Editions.), Abstracts, B 12-4". Proceedings of EUREM 11.3 (1996): 327.

68. Coulic V., et al. "Degenerative and regenerative processes in fetal organ ectopic growth". Analytical Cellular Pathology 18.1 (1999): A046.

69. Coulic V., et al. "The first phase of the syngeneic fœtal organ implant development: crucial and mysterious process". $A b$ stracts 14th Heidelberg Cytometry Symposium (HCS) (2001): 18-20. 
70. Coulic V., et al. "Growth factors and fetal digestive organ implants development". Acta Gastroenterologica Belgica 64.1 (2001): B2.

71. Coulic V., et al. "Foetal liver syngenic transplantation (First report), XVth Belgian Week of Gastroenterology (Abstracts)". Acta Gastro-enterologica Belgica 66.1 (2003): B01.

72. Lupp A., et al. "Evaluation of 2-year-old intrasplenic fetal liver tissue transplant in rats". Cell Transplantation 12 (2003): 423438.

73. Coulic V., et al. "Syngenic transplantation of fetal liver". European Journal of Internal Medicine 14.1 (2003): S23.

74. Canete A., et al. "Characterization of a fetal liver cell population endowed with long-term multiorgan endothelial reconstitution potential". Stem Cells 65.2 (2017): 507-521.

75. Gianotti A., et al. "Functions and emerging role of the foetal liver in regenerative medicine". Cells 8 (2019): 914.

76. Uyama K., et al. "Lung regeneration by fetal lung tissue implantation in a mouse pulmonary emphysema model". The Journal of Medical Investigation 63.3-4 (2016): 182-186.

77. Chang YH., et al. "Transplantation if foetal kidney tissue reduces cerebral infarction induced by middle cerebral artery ligation". Journal of Cerebral Blood Flow and Metabolism 19.12 (1999): 1359-1335.

78. Rowley JD., et al. "Harmful moratorium on stem cell research". Science 297.5589 (2002): 1957.

79. Regala C., et al. "Xenografted fetal dorsal root ganglion, embryonic stem cell and adult neural stem cell survival following implantation into the vestibulocochlear nerve". Experimental Neurology 193.2 (2005): 326-333.

80. Coulic V., et al. "Is incidental teratoma growth possible after syngeneic foetal organ implantation in the adult rat?" Journal of Medical Research and Practice 2.4 (2013): 7-13.

81. Coulic V., et al. "Once more about syngenic fotal organ grafting and teratoma formation". Acta Scientific Gastrointestinal Disorders 2.5 (2019): 39-47.

82. De WG and Mannery C. "Human embryonic stem cells: research, ethics and policy". Human Reproduction 18.4 (2003): 672-682.

83. Coulic V. "Ethics and experimental Medicine". J PDT, and in 'Current Trends in Medicine and Medical Research 9 (2015): 8.
Volume 3 Issue 7 July 2021

C All rights are reserved by Coulic Véry., et al. 